OPEN ACCESS

Edited by:

Aixin Yan,

University of Hong Kong, Hong Kong

Reviewed by:

Yigang Tong,

Beijing Institute of Microbiology and Epidemiology, China

Jingmin Gu,

Jilin University, China

*Correspondence.

Fuquan $\mathrm{Hu}$

hufuquan2009@yahoo.cn

Yang $\mathrm{Li}$

dpliyang@tmmu.edu.cn

Specialty section:

This article was submitted to Antimicrobials, Resistance

and Chemotherapy,

a section of the journa

Frontiers in Microbiology

Received: 28 May 2018

Accepted: 16 July 2018

Published: 03 August 2018

Citation:

Yang Y, Le S, Shen W, Chen $Q$, Huang Y, Lu S, Tan Y, Li M, Hu F and Li Y (2018) Antibacterial Activity of a

Lytic Enzyme Encoded by

Pseudomonas aeruginosa Double Stranded RNA Bacteriophage phiYY.

Front. Microbiol. 9:1778.

doi: 10.3389/fmicb.2018.01778

\section{Antibacterial Activity of a Lytic Enzyme Encoded by Pseudomonas aeruginosa Double Stranded RNA Bacteriophage phiYY}

\author{
Yuhui Yang', Shuai Le', Wei Shen'2, Qian Chen ${ }^{3}$, Youying Huang ${ }^{3}$, Shuguang Lu', \\ Yinling Tan', Ming $\mathrm{Li}^{1}$, Fuquan $\mathrm{Hu}^{1 *}$ and Yang $\mathrm{Li}^{4 *}$
}

${ }^{1}$ Department of Microbiology, Army Medical University, Chongqing, China, ${ }^{2}$ Department of Medical Laboratory, Chengdu Military General Hospital, Chengdu, China, ${ }^{3}$ Biomedical Analysis Center, Army Medical University, Chongqing, China, ${ }^{4}$ Trauma Center of PLA, State Key Laboratory of Trauma, Burns and Combined Injury, Institute of Surgery Research, Daping Hospital, Army Medical University, Chongqing, China

Multidrug-resistant Pseudomonas aeruginosa is one of the most life-threatening pathogens for global health. In this regard, phage encoded lytic proteins, including endolysins and virion-associated peptidoglycan hydrolases (VAPGH), have been proposed as promising antimicrobial agents to treat $P$. aeruginosa. Most dsDNA phages use VAPGH to degrade peptidoglycan (PG) during infection, and endolysin to lyse the host cells at the end of lytic cycle. By contrast, dsRNA phage encodes only one lytic protein, which is located in the viral membrane to digest the PG during penetration, and also serves as an endolysin to release the phage. Currently, there are only seven sequenced dsRNA phages, and phiYY is the only one that infects human pathogen $P$. aeruginosa. In this study, dsRNA phage phiYY encoded lysin, named Ply17, was cloned and purified. Ply17 contains a PG-binding domain and a lysozyme-like-family domain. Ply17 exhibited a broad antibacterial activity against the outer membrane permeabilizer treated Gram-negative bacteria. The best lytic activity was achieved at $37^{\circ} \mathrm{C}, \mathrm{pH} 7.5$, in the presence of $0.5 \mathrm{mM}$ EDTA. Moreover, it could effectively lyse Gram-positive bacteria directly, including Staphylococcus aureus. Therefore, dsRNA phage encoded Ply17 might be a promising new agent for treating multidrug-resistant pathogens.

Keywords: dsRNA bacteriophage, Pseudomonas aeruginosa, lysin, VAPGH, antibacterial activity

\section{INTRODUCTION}

Pseudomonas aeruginosa is one of the most life-threatening opportunistic pathogens that cause infections of bloodstream, urinary tract, burn wound, as well as airway of cystic fibrosis patient (Jonckheere et al., 2018; Waters and Grimwood, 2018). Moreover, the emergence and increase of multidrug resistance in clinical isolates are worrying (Alessa et al., 2018). Thus, alternative treatments are needed to cope with this problem, and bacteriophage (phage) and phage derived lysin are promising antimicrobial agents (Lood et al., 2015; Forti et al., 2018; Gutierrez et al., 2018). 
Phages are viruses that specifically infect bacteria (Salmond and Fineran, 2015). There are two major weapons utilized by phage to break the bacterial cell wall. In the initial step of infection, phage uses virion-associated peptidoglycan hydrolases (VAPGH) to slightly degrade peptidoglycan (PG) to inject the phage genetic material into the cell (Rodriguez-Rubio et al., 2013; Latka et al., 2017). At the end of infection cycle, phage encoded holin forms pores in the inner membrane, and followed by access of endolysin to the cell wall where it degrades PG (Gerstmans et al., 2017). Then cell lysed and the mature phage particle released. Thus, endolysin and VAPGH are promising alternative antimicrobial agents, and there are renewed interests in studying and exploiting their potentials in combating pathogens (Defraine et al., 2016; SaoJose, 2018).

Endolysin has been extensively studied in the last decade. Most phage endolysin possess a cell wall binding domain (CBD) and one or two catalytic domains, which can be classified into six different types according to the cleaving activity against PG (Gutierrez et al., 2018). Endolysin has been shown to be active in killing pathogens (Becker et al., 2016), degrading biofilms (Gutierrez et al., 2014) and protecting animal models from pathogen infection (Lood et al., 2015).

Compared with endolysin, VAPGH is less studied, but its therapeutic value has attracted more attention recently (Rodriguez-Rubio et al., 2013; Latka et al., 2017). To inject genomes into bacterial cytoplasm, phages have to degrade the PG through VAPGH, which has been classified into three categories base on the cleaving site on PG, including glycosidases, amidases, and endopeptidases (Latka et al., 2017). Majority of the VAPGH are glycosidases, such as Gp16 from phage T7 (Moak and Molineux, 2000). The most common locations of VAPGH in the viron is phage tail and baseplate to facilitate the degradation of $P G$ after phage adsorption (Briers et al., 2008). And for membrane-containing phages, VAPGH are located in the viral membrane, such as Gp5 in phage phi6 (Caldentey and Bamford, 1992). VAPGH has been shown to be active against Gram-positive bacteria, such as Staphylococcus aureus (Rashel et al., 2008; Rodriguez-Rubio et al., 2012), and can also kill outer membrane-permeabilized Gram-negative bacteria, such as $P$. aeruginosa (Lavigne et al., 2004).

Most DNA phages encode endolysin and VAPGH separately. Interestingly, dsRNA phages phi6 and phil3 encode only one lytic protein, which is located in the viral membrane to digest the PG during penetration, and also serves as an endolysin to release the phage (Caldentey and Bamford, 1992; Daugelavicius et al., 2005). Currently, only seven dsRNA phages have been sequenced, and phiYY is the only one that infects human pathogen $P$. aeruginosa (Yang et al., 2016), while other six dsRNA phages infect Pseudomonas syringae (Mantynen et al., 2018). In this study, the dsRNA phage phiYY encoded lysin, named Ply17, was purified and its antimicrobial activity was tested against a panel of pathogens.

\section{MATERIALS AND METHODS}

\section{Bacterial Strains and Culture Conditions}

Pseudomonas aeruginosa PAO1 and lytic phage phiYY (Yang et al., 2016) were stored in our laboratory at $-80^{\circ} \mathrm{C}$ in glycerol. P. aeruginosa clinical isolated strains (Sun et al., 2013), Escherichia coli, S. aureus (Zhang et al., 2014), and Staphylococcus epidermidis strains were routinely grown in Luria-Bertani (LB) broth with aeration at $37^{\circ} \mathrm{C}$.

\section{Ply17 Protein Purification}

The Ply17 gene was amplified by PCR, using cDNA of phiYY genome as template. The PCR primers were Ply17-F: 5' GGGAATTCCATATGGCTGCCCAGGGTCGC-3' and Ply17-R: 5'-CGGAATTCTGCGAATAGAGCT-3'. The PCR product was purified and digested with NdeI/EcoRI. The digested PCR product was then ligated into NdeI/EcoRI-treated PET-28a to generate pET-Ply17, which was transferred into $E$. coli BL21(DE3) and selected on LB agar containing kanamycin (50 $\mu \mathrm{g} / \mathrm{ml})$.

To induce the expression of His-tagged Ply17, transformed E. coli strain was cultured in LB containing $50 \mu \mathrm{g} / \mathrm{ml}$ kanamycin until $\mathrm{OD}_{600}=0.6$. Then, $0.5 \mathrm{mM}$ IPTG was used to induce the expression of Ply17. After $12 \mathrm{~h}$ induction at $37^{\circ} \mathrm{C}$, cells were pelleted and the His-tagged Ply17 was purified through Ni-NTA column as previously described (Dong et al., 2015).

Purified protein was confirmed by SDS/PAGE stained with Coomassie Brilliant Blue and stored at $-80^{\circ} \mathrm{C}$ after the buffer was changed to storage buffer (20 mM Tris- $\mathrm{HCl}, 100 \mathrm{mM} \mathrm{NaCl}, 10 \%$ glycerol, $\mathrm{pH}$ 7.5) by ultrafiltration.

\section{Determination of the Antimicrobial Activity}

The antimicrobial activity of Ply17 was determined by colony forming units (CFU) reduction analysis as previously described (Rodriguez et al., 2011; Dong et al., 2015). For Gram-negative bacteria, early log phase cells were pelleted and resuspended in $20 \mathrm{mM}$ Tris-HCl buffer ( $\mathrm{pH}$ 7.5) supplemented with $0.1 \mathrm{M}$ EDTA for $5 \mathrm{~min}$ at room temperature. The high concentration of EDTA is toxic to the cells, thus $5 \mathrm{~min}$ is applied to treat the outer membrane. Then, cells were pelleted and washed with $20 \mathrm{mM}$ Tris- $\mathrm{HCl}$ buffer three times to remove the remaining EDTA. Next, $20 \mu \mathrm{l}$ of Ply17 $(5 \mathrm{mg} / \mathrm{ml}$ ) was added into $80 \mu \mathrm{l}$ of resuspended bacteria with a final concentration of Ply17 as $1 \mathrm{mg} / \mathrm{ml}$. After $30 \mathrm{~min}$ incubation at $37^{\circ} \mathrm{C}$, the mixture was serially diluted by 10 -fold and plated on LB agar plates. Then, CFU was calculated after $24 \mathrm{~h}$ incubation to determine the viable cell number.

Factors affecting Ply17 function were analyzed using early log phase bacteria under different reaction conditions, including Ply17 concentration (0-1.5 mg/ml), pH (4.0-11.0).

To test the synergism between EDTA and Ply17, $0.1 \mathrm{M}$ EDTA-treated PAO1 was mixed with $1 \mathrm{mg} / \mathrm{ml}$ Ply17 in the 


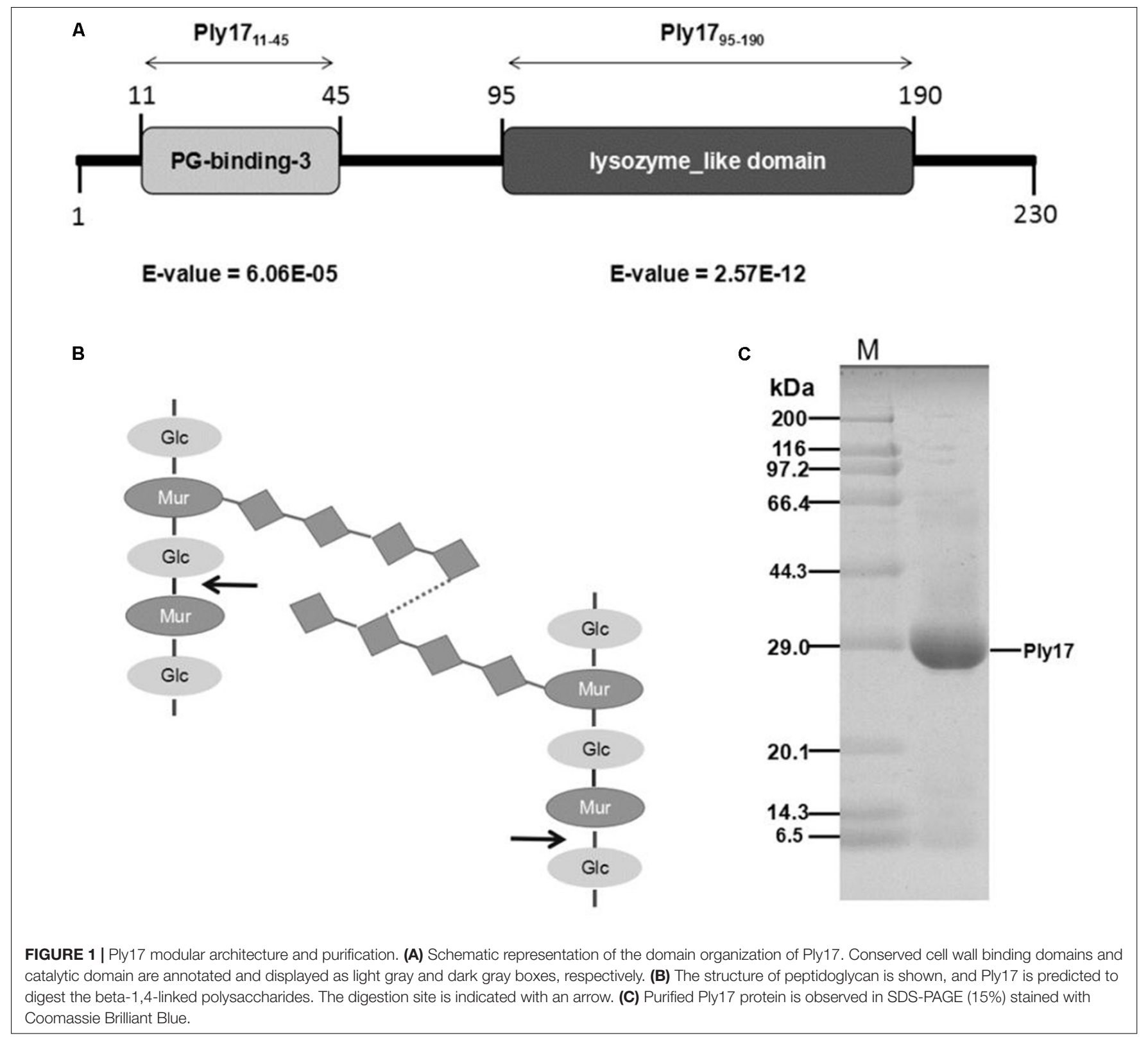

presence of different EDTA concentrations (0-5.0 mM) for $30 \mathrm{~min}$ at $37^{\circ} \mathrm{C}$. Then, $\mathrm{CFU}$ was calculated after $24 \mathrm{~h}$ cultivation.

To test the thermal stability, Ply17 was incubated at different temperatures $\left(30-90^{\circ} \mathrm{C}\right)$ for $10 \mathrm{~min}$. Then, use the standard condition to test its lytic activity through $\mathrm{CFU}$ reduction analysis.

To test the lytic activity against Gram-positive bacteria, cells were pelleted and resuspended in $20 \mathrm{mM}$ Tris- $\mathrm{HCl}$ buffer ( $\mathrm{pH}$ 7.5) without EDTA. Then $20 \mu \mathrm{l}$ of Ply17 $(5 \mathrm{mg} / \mathrm{ml})$ was added into $80 \mu \mathrm{l}$ of resuspended bacteria. The remaining protocol is same as treating Gram-negative bacteria as described previously. All experiments were repeated three times. The values are the means and standard deviations from triplicate assays.

\section{RESULTS}

\section{Ply17 Sequence Analysis and Protein Purification}

Genome annotation revealed a putative muramidase, named Ply17, in the phiYY genome segment S (NCBI: KX074203.1). Ply17 is also detected in the viral particles by HPLC-MS after SDS-PAGE, indicating that Ply17 is viron associated (Yang et al., 2016).

In silico analysis of Ply17 predicted a 230-amino acid protein $(25.2 \mathrm{kDa})$ with two independent domains: the PGbinding domain and lysozyme-like-family domain (Figure 1A). The PG-binding domain is responsible for cell wall binding, which is present in most endolysins, but absented in VAPGHs. 
The lysozyme-like-family domain is similar to muramidase of dsRNA phage phi13, with a predicted function of hydrolysis of beta-1,4-linked polysaccharides (Figure 1B).

Ply17 with a His-tag at the C-terminus was purified from E. coli cells bearing an IPTG-inducible expression plasmid pETPly17. The purified protein band was observed with correct mass $(25.2 \mathrm{kDa})$, as was determined by SDS/PAGE stained with Coomassie Brilliant Blue (Figure 1C).

\section{Lytic Activity of Ply17}

The antibacterial activity of Ply17 was tested by CFUs reduction assay (Dong et al., 2015), using P. aeruginosa strain PAO1 as target. Gram-negative bacterium is rarely sensitive to endolysin due to the outer membrane barrier. Thus, $0.1 \mathrm{M}$ EDTA was used as outer membrane permeabilizer to treat PAO1. Our data showed that, in the presence of permeabilizer, Ply17 induced PAO1 lysis and the viable cell significantly decreased after 30 min treatment, while no killing was observed in the absence of EDTA (Figure 2A). Meanwhile, different concentrations of Ply17 were tested. The addition of $500 \mu \mathrm{g} / \mathrm{ml}$ Ply17 reduced the viable numbers of EDTAtreated PAO1 by 1 log unit, while the most significant reduction was observed when $1 \mathrm{mg} / \mathrm{ml}$ Ply17 was used (Figure 2B). These data further confirmed the antimicrobial activity of Ply17.

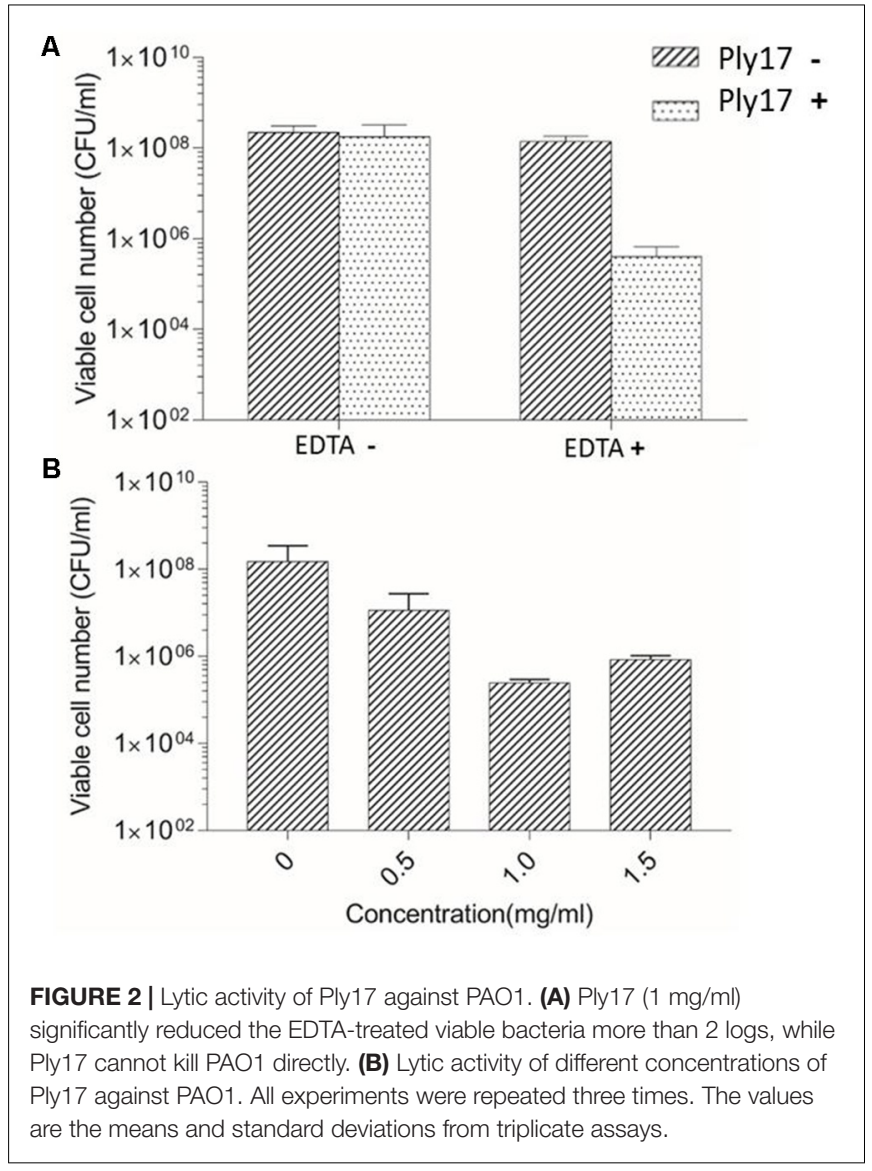

\section{Influence of EDTA, Temperature, and pH on Ply17 Antibacterial Activity}

To test the thermal stability of lysin, Ply17 was incubated under different temperatures for $10 \mathrm{~min}$, then cooled to room temperature and used to test its antimicrobial activity under $37^{\circ} \mathrm{C}$. The results showed that Ply17 is stable under $40^{\circ} \mathrm{C}$, but its activity significantly decreased after heat-treatment at $50^{\circ} \mathrm{C}$ (Figure 3A).

Meanwhile, EDTA has a synergistic effect with Ply17 in killing PAO1. As the concentration of EDTA in the reaction buffer increased to $0.5 \mathrm{mM}$, the antibacterial activity of Ply17 increased accordingly, but plateaued after that concentration (Figure 3B).

The low $\mathrm{pH}$ values of the reaction buffer significantly affect cell viability, while the relative high lytic activity was observed at $\mathrm{pH}$ value of 7.5-8, with a reduction of 3-4 $\log$ units of viable cells compared to no Ply17 addition control (Figure 3C). The isoelectric point of Ply17 is predicted to be 7.0. Thus, its activity is significantly impaired at $\mathrm{pH}$ 7.0.

\section{The Broad Bactericidal Activity of Ply17}

The activity spectrum of Ply17 against different $P$. aeruginosa strains and other bacterial species is shown in Figure 4. The viabilities of the 12 clinical isolates of $P$. aeruginosa (Sun et al., 2013) and two E. coli strains (JM110 and JM109) reduced 1-4 log unit following the incubation with Ply17 for $30 \mathrm{~min}$.

To test whether Ply17 is active against Gram-positive bacteria, Ply17 was added to S. aureus strain (N315, XN108; Zhang et al., 2014) and S. epidermidis strain SE1 without EDTA treatment, because the PG of Gram-positive is exposed without outer membrane. As shown in Figures 4, 5, Ply17 was able to lyse all three Gram-positive strains and reduced the viable cells by 2 log units. Representative pictures of cell viability before and after Ply17 treatment are shown in Figure 5.

\section{DISCUSSION}

In this study, we reported the antibacterial activity of a lytic enzyme Ply17 encoded by double stranded RNA bacteriophage phiYY (Yang et al., 2016). Lysin is usually classified into endolysin and VAPGH, based on their different functions in the phage infection cycle (Gutierrez et al., 2018). However, lysin encoded by dsRNA phage is quite unique. It is located in the viron membrane to degrade the PG during the initial infection process, and also serves as endolysin at the final step of phage infection cycle (Daugelavicius et al., 2005). Currently, lysin P5 from phi6 is the only lysin isolated from dsRNA phage, and it was purified from disrupted viral particles (Caldentey and Bamford, 1992). In this study, we successfully purified phiYY encoded lysin Ply17 with a His-tag at the C-terminus from $E$. coli cells bearing an IPTG-inducible expression plasmid pETPly17.

The antimicrobial activity of Ply17 was confirmed by its ability to reduce the viability of $P$. aeruginosa PAO1 (Figure 2). However, all the Gram-negative bacteria possess outer membrane 

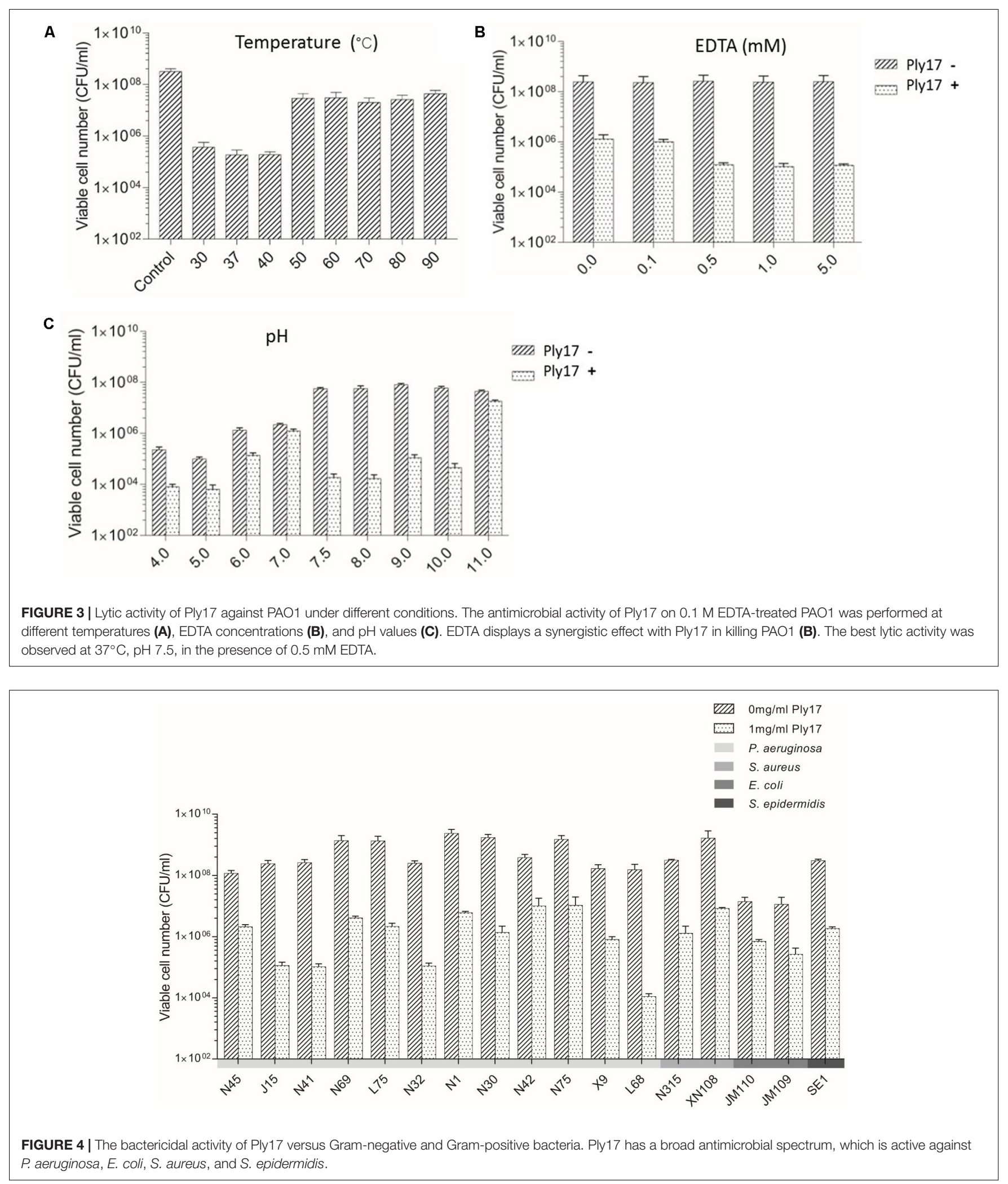

to prevent the entry of lysin into the cell wall (Nikaido, 2003), thus Ply17 cannot kill $P$. aeruginosa directly (Figure 2A). Our data showed that, when pre-treated with EDTA, a chelator which disrupts the outer membrane by removing the stabilizing cations (Oliveira et al., 2014; Dong et al., 2015), Ply17 significantly reduced the cell viability, confirming its antimicrobial activity. 


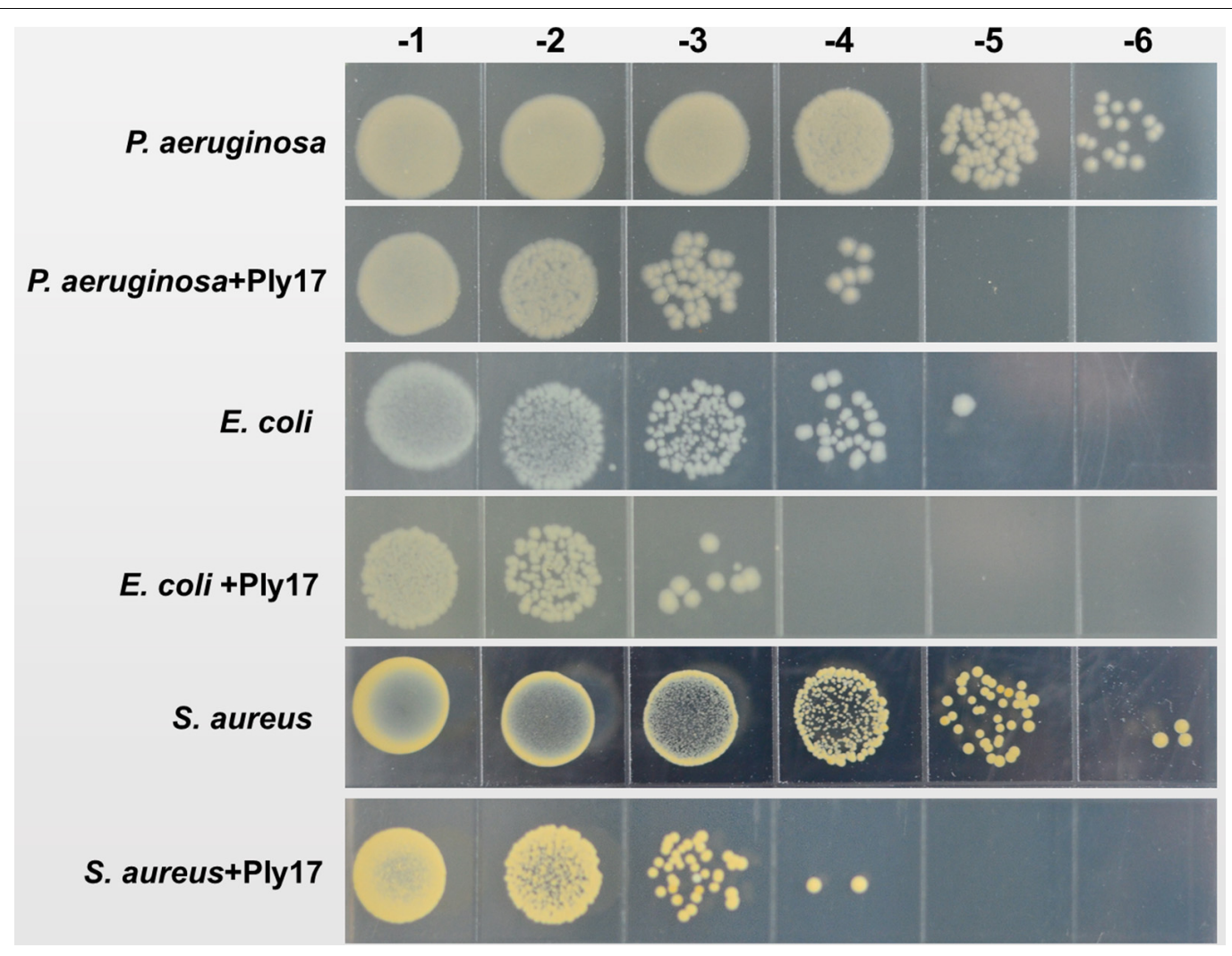

FIGURE 5 | Representative pictures of cell viability before and after Ply17 treatment. To measure viability, 10-fold dilutions of log phase bacteria and Ply17-treated cells were spotted onto agar plates. Representative pictures of $P$. aeruginosa PAO1, E. coli JM109, and S. aureus XN108 showed that Ply17 reduced the viable cell by $\sim 2 \log$ units.

Lysin Ply17 showed a broad lytic activity against both Gram-positive and Gram-negative species (Figure 4), including $P$. aeruginosa, E. coli, S. aureus, and S. epidermidis. In contrast, dsRNA phage phi6 encoded lysin P5 only lyses Gramnegative bacteria, but not Gram-positive bacteria (Caldentey and Bamford, 1992). One possible reason could be due to their differences in the cleaving site specificity. Lysin P5 from phage phi6 acts on the peptide component of PG, which is quite diverse in Gram-positive bacteria (Alcorlo et al., 2017). On the contrary, lysin Ply17 was predicted to contain a lysozyme-like-family domain, which cleaves the beta-1,4-linked polysaccharides. The polysaccharides chain is made up of $\mathrm{N}$-acetylglucosamine and $\mathrm{N}$-acetylmuramic acid residues linked by beta-1,4 glycosidic bonds, which is very conservative (Pazos et al., 2017). Thus, Ply17 can directly cleaves the PG of Gram-positive bacteria without EDTA treatment (Figure 5).

To target Gram-negative bacteria infection, lysin must pass through the outer membrane. Some lysins possess this capability. For example, Acinetobacter baumannii phage lysin PlyF307 is active against all clinical strains of A. baumannii, and the killing is outer membrane permeabilizer independent (Lood et al., 2015). The molecular mechanism is yet to be determined. But the C-terminal region of PlyF307 contains a positively charged outer membrane-destabilizing domain, which might play a role. Moreover, engineered lysin can also penetrate the outer membrane (Sao-Jose, 2018). Artilysin is a novel engineered lysin, which consists of an endolysin and a specific lipopolysaccharide destabilizing peptide that can translocate the endolysin into cell wall (Gerstmans et al., 2016). Therefore, artilysin can directly kill both Gram-positive and Gram-negative bacteria with high efficiency (Defraine et al., 2016; Schirmeier et al., 2018). Thus, further engineering of Ply17 might improve its ability to kill Gram-negative bacteria and enhance its killing efficiency against Gram-positive pathogens.

\section{AUTHOR CONTRIBUTIONS}

YL and FH conceived the study. YY, SLe, and WS performed the experiments. SLu, YT, and ML analyzed the data. QC and $\mathrm{YH}$ provided intellectual support. SLe wrote the paper. All authors read and approved the final manuscript for publication.

\section{FUNDING}

This work was supported by Chongqing Science and Technology Commission (cstc2016shmszx130022). 


\section{REFERENCES}

Alcorlo, M., Martinez-Caballero, S., Molina, R., and Hermoso, J. A. (2017). Carbohydrate recognition and lysis by bacterial peptidoglycan hydrolases. Curr. Opin. Struct. Biol. 44, 87-100. doi: 10.1016/j.sbi.2017.01.001

Alessa, M. A., Almangour, T. A., Alhossan, A., Alkholief, M. A., Alhokail, M., and Tabb, D. E. (2018). Ceftolozane-tazobactam for the treatment of multidrug-resistant Pseudomonas aeruginosa pneumonia in a patient receiving intermittent hemodialysis. Am. J. Health Syst. Pharm. 75, e184-e188. doi: 10. 2146/ajhp170056

Becker, S. C., Roach, D. R., Chauhan, V. S., Shen, Y., Foster-Frey, J., Powell, A. M., et al. (2016). Triple-acting lytic enzyme treatment of drug-resistant and intracellular Staphylococcus aureus. Sci. Rep. 6:25063. doi: 10.1038/srep25063

Briers, Y., Miroshnikov, K., Chertkov, O., Nekrasov, A., Mesyanzhinov, V., Volckaert, G., et al. (2008). The structural peptidoglycan hydrolase gp181 of bacteriophage phiKZ. Biochem. Biophys. Res. Commun. 374, 747-751. doi: 10. 1016/j.bbrc.2008.07.102

Caldentey, J., and Bamford, D. H. (1992). The lytic enzyme of the Pseudomonas phage phi 6. Purification and biochemical characterization. Biochim. Biophys. Acta 1159, 44-50. doi: 10.1016/0167-4838(92)90073-M

Daugelavicius, R., Cvirkaite, V., Gaidelyte, A., Bakiene, E., GabrenaiteVerkhovskaya, R., and Bamford, D. H. (2005). Penetration of enveloped double-stranded RNA bacteriophages phil3 and phi6 into Pseudomonas syringae cells. J. Virol. 79, 5017-5026. doi: 10.1128/JVI.79.8.5017-5026.2005

Defraine, V., Schuermans, J., Grymonprez, B., Govers, S. K., Aertsen, A., Fauvart, M., et al. (2016). Efficacy of artilysin Art-175 against resistant and persistent Acinetobacter baumannii. Antimicrob. Agents Chemother. 60, 34803488. doi: 10.1128/AAC.00285-16

Dong, H., Zhu, C., Chen, J., Ye, X., and Huang, Y. P. (2015). Antibacterial activity of Stenotrophomonas maltophilia endolysin P28 against both gram-positive and gram-negative bacteria. Front. Microbiol. 6:1299. doi: 10.3389/fmicb.2015. 01299

Forti, F., Roach, D. R., Cafora, M., Pasini, M. E., Horner, D. S., Fiscarelli, E. V., et al. (2018). Design of a broad-range bacteriophage cocktail that reduces Pseudomonas aeruginosa biofilms and treats acute infections in two animal models. Antimicrob. Agents Chemother. 62, e02573-17. doi: 10.1128/AAC. 02573- 17

Gerstmans, H., Criel, B., and Briers, Y. (2017). Synthetic biology of modular endolysins. Biotechnol. Adv. 36, 624-640. doi: 10.1016/j.biotechadv.2017.12.009

Gerstmans, H., Rodriguez-Rubio, L., Lavigne, R., and Briers, Y. (2016). From endolysins to artilysin(R)s: novel enzyme-based approaches to kill drugresistant bacteria. Biochem. Soc. Trans. 44, 123-128. doi: 10.1042/BST20150192

Gutierrez, D., Fernandez, L., Rodriguez, A., and Garcia, P. (2018). Are phage lytic proteins the secret weapon to kill Staphylococcus aureus? mBio 9, e01923-17. doi: 10.1128/mBio.01923-17

Gutierrez, D., Ruas-Madiedo, P., Martinez, B., Rodriguez, A., and Garcia, P. (2014). Effective removal of staphylococcal biofilms by the endolysin LysH5. PLoS One 9:e107307. doi: 10.1371/journal.pone.0107307

Jonckheere, L., Schelstraete, P., Van Simaey, L., Van Braeckel, E., Willekens, J., Van Daele, S., et al. (2018). Establishing the diagnosis of chronic colonization with Pseudomonas aeruginosa of cystic fibrosis patients: comparison of the European consensus criteria with genotyping of P. aeruginosa isolates. J. Cyst. Fibros. doi: 10.1016/j.jcf.2018.03.004 [Epub ahead of print].

Latka, A., Maciejewska, B., Majkowska-Skrobek, G., Briers, Y., and Drulis-Kawa, Z. (2017). Bacteriophage-encoded virion-associated enzymes to overcome the carbohydrate barriers during the infection process. Appl. Microbiol. Biotechnol. 101, 3103-3119. doi: 10.1007/s00253-017-8224-6

Lavigne, R., Briers, Y., Hertveldt, K., Robben, J., and Volckaert, G. (2004). Identification and characterization of a highly thermostable bacteriophage lysozyme. Cell. Mol. Life Sci. 61, 2753-2759. doi: 10.1007/s00018-004-4301-y

Lood, R., Winer, B. Y., Pelzek, A. J., Diez-Martinez, F., Thandar, M., Euler, C. W., et al. (2015). Novel phage lysin capable of killing the multidrug-resistant gram-negative bacterium Acinetobacter baumannii in a mouse bacteremia model. Antimicrob. Agents Chemother. 59, 1983-1991. doi: 10.1128/AAC. 04641-14

Mantynen, S., Sundberg, L. R., and Poranen, M. M. (2018). Recognition of six additional cystoviruses: Pseudomonas virus phi6 is no longer the sole species of the family Cystoviridae. Arch. Virol. 163, 1117-1124. doi: 10.1007/s00705017-3679-4

Moak, M., and Molineux, I. J. (2000). Role of the Gp16 lytic transglycosylase motif in bacteriophage T7 virions at the initiation of infection. Mol. Microbiol. 37, 345-355. doi: 10.1046/j.1365-2958.2000.01995.x

Nikaido, H. (2003). Molecular basis of bacterial outer membrane permeability revisited. Microbiol. Mol. Biol. Rev. 67, 593-656. doi: 10.1128/MMBR.67.4.593656.2003

Oliveira, H., Thiagarajan, V., Walmagh, M., Sillankorva, S., Lavigne, R., NevesPetersen, M. T., et al. (2014). A thermostable Salmonella phage endolysin, Lys68, with broad bactericidal properties against gram-negative pathogens in presence of weak acids. PLoS One 9:e108376. doi: 10.1371/journal.pone.0108376

Pazos, M., Peters, K., and Vollmer, W. (2017). Robust peptidoglycan growth by dynamic and variable multi-protein complexes. Curr. Opin. Microbiol. 36, 55-61. doi: 10.1016/j.mib.2017.01.006

Rashel, M., Uchiyama, J., Takemura, I., Hoshiba, H., Ujihara, T., Takatsuji, H., et al. (2008). Tail-associated structural protein gp61 of Staphylococcus aureus phage phi MR11 has bifunctional lytic activity. FEMS Microbiol. Lett. 284, 9-16. doi: $10.1111 / j .1574-6968.2008 .01152 . x$

Rodriguez, L., Martinez, B., Zhou, Y., Rodriguez, A., Donovan, D. M., and Garcia, P. (2011). Lytic activity of the virion-associated peptidoglycan hydrolase HydH5 of Staphylococcus aureus bacteriophage vB_SauS-phiIPLA88. BMC Microbiol. 11:138. doi: 10.1186/1471-2180-11-138

Rodriguez-Rubio, L., Martinez, B., Donovan, D. M., Rodriguez, A., and Garcia, P. (2013). Bacteriophage virion-associated peptidoglycan hydrolases: potential new enzybiotics. Crit. Rev. Microbiol. 39, 427-434. doi: 10.3109/1040841X.2012. 723675

Rodriguez-Rubio, L., Martinez, B., Rodriguez, A., Donovan, D. M., and Garcia, P. (2012). Enhanced staphylolytic activity of the Staphylococcus aureus bacteriophage vB_SauS-phiIPLA88 HydH5 virion-associated peptidoglycan hydrolase: fusions, deletions, and synergy with LysH5. Appl. Environ. Microbiol. 78, 2241-2248. doi: 10.1128/AEM.07621-11

Salmond, G. P. C., and Fineran, P. C. (2015). A century of the phage: past, present and future. Nat. Rev. Microbiol. 13, 777-786. doi: 10.1038/nrmicro3564

Sao-Jose, C. (2018). Engineering of phage-derived lytic enzymes: improving their potential as antimicrobials. Antibiotics 7:E29. doi: 10.3390/antibiotics7020029

Schirmeier, E., Zimmermann, P., Hofmann, V., Biebl, M., Gerstmans, H., Maervoet, V. E. T., et al. (2018). Inhibitory and bactericidal effect of $\operatorname{artilysin}((\mathrm{R}))$ Art-175 against colistin-resistant mcr-1-positive Escherichia coli isolates. Int. J. Antimicrob. Agents 51, 528-529. doi: 10.1016/j.ijantimicag.2017. 08.027

Sun, F. J., Shi, H. Q., Zhang, X. B., Fang, Y. D., Chen, Y. C., Chen, J. H., et al. (2013). Detection of carbapenemase-encoding genes among clinical isolates of pseudomonas aeruginosa in a Chinese burn unit. J. Burn Care Res. 34, 453-458. doi: 10.1097/BCR.0b013e3182700afd

Waters, V., and Grimwood, K. (2018). Defining chronic Pseudomonas aeruginosa infection in cystic fibrosis. J. Cyst. Fibros. 17, 292-293. doi: 10.1016/j.jcf.2018. 03.007

Yang, Y. H., Lu, S. G., Shen, W., Zhao, X., Shen, M. Y., Tan, Y. L., et al. (2016). Characterization of the first double-stranded RNA bacteriophage infecting Pseudomonas aeruginosa. Sci. Rep. 6:38795. doi: 10.1038/srep38795

Zhang, X., Xu, X., Yuan, W., Hu, Q., Shang, W., Hu, X., et al. (2014). Complete genome sequence of Staphylococcus aureus XN108, an ST239-MRSA-SCCmec III strain with intermediate vancomycin resistance isolated in mainland China. Genome Announc. 2:e00449-14. doi: 10.1128/genomeA.00449-14

Conflict of Interest Statement: The authors declare that the research was conducted in the absence of any commercial or financial relationships that could be construed as a potential conflict of interest.

Copyright (๑) 2018 Yang, Le, Shen, Chen, Huang, Lu, Tan, Li, Hu and Li. This is an open-access article distributed under the terms of the Creative Commons Attribution License (CC BY). The use, distribution or reproduction in other forums is permitted, provided the original author(s) and the copyright owner(s) are credited and that the original publication in this journal is cited, in accordance with accepted academic practice. No use, distribution or reproduction is permitted which does not comply with these terms. 